(c) Kotelnikov G.P., Ryzhov P.V., Lartsev Yu.V., Zuev-Ratnikov S.D., Kudashev D.S., ZelterP.M., Shmelkov A.V., Bagdulina O.D., 2020

DOI 10.18019/1028-4427-2020-26-3-319-324

\title{
Preoperative planning of severe recurrent patellar dislocation in children
}

\author{
G.P. Kotelnikov, P.V. Ryzhov, Yu.V. Lartsev, S.D. Zuev-Ratnikov, D.S. Kudashev, P.M. Zelter, \\ A.V. Shmelkov, O.D. Bagdulina
}

Samara State Medical University, Samara, Russian Federation

\begin{abstract}
Introduction The patellofemoral joint is a complex structure. Dysplasia of the trochlea and the adjacent portions of the lower limb has been shown to predispose pediatric patients to severe recurrent patellar dislocation. The comprehensive diagnostic workup has important implications for determining treatment of a complex multicomponent deformity of the patellofemoral joint in severe recurrent patellar dislocation. The objective of the study was to develop a preoperative diagnostic protocol for optimal surgical treatment of pediatric patients with severe recurrent patellar dislocation to enable complication rate reduction. Material and methods Between 2015 and 201754 patients diagnosed with patellar dislocation were treated at the Samara State Medical University hospital. Severe patellar dislocation according to the Volkov classification was identified in 37 patients. Patients were evaluated according to the algorithm described in the article and treated appropriately based on the findings. Results Multiplanar pathological changes were detected in the patellofemoral joint of all participants. The patients underwent supracondylar derotational varus osteotomy of the femur combined with a tibial tubercle medialization osteotomy to address multiplanar deformity. No complications were seen in 32 patients at a long term and re-dislocation occurred in one case. Four patients developed a contracture of the knee joint due to inadequate postoperative rehabilitation. Conclusion The thorough diagnostic workup is crucial for identifying treatment strategy of a recurrent patellar dislocation due to a complex structure of the patellofemoral joint and a multicomponent deformity at the anatomical site to avoid postoperative complications.
\end{abstract}

Keywords: dislocation of the patella, recurrent, diagnosis, flat-valgus deformation of the feet, surgical treatment

\section{INTRODUCTION}

The patellofemoral joint movements feature high degrees of freedom due tothe structure of articular surfaces and ligaments. Normal function of the patellofemoral joint is ensured by passive stabilizers (femoral trochlae and the retinaculum) and active stabilizers (the quadriceps muscles). Patellar stability during knee range of motion is responsible for biomechanical balance of the musculoskeletal system [1].

Patellar dislocation is common among adolescents 10 to 17 years old. Acute traumatic patellar dislocation accounts for approximately $2.44 \%$ of all knee injuries [2]. About $49 \%$ of first time dislocations had recurrent patellar instability episodes [2]. Neglected patellar redislocation in children can cause valgus deformity of the knee joint that can result in evident progression of impaired limb function. Many researchers agree that changes in the anatomy of the hip and knee joints, foot and ankle deformities resulting from skeletal dysplasia predispose pediatric and adolescent patients to recurrent patellar dislocation [3]. Nonoperative approaches are most often suitable for first-time patellar dislocations
[4]. Surgical treatment is recommended for patellar realignment in the setting of recurrent instability with reconstructive and plasty surgeries indicated in almost $100 \%$ of the patients with redislocation. The surgical option woud be dependent on the severity of pathological changes. The Volkov grading system classifies mild, moderate and severe dislocations. There are nearly 130 types of procedures known to address patellar dislocations. Despite substantial technological and surgical advances, the postoperative complications are reported to occur in $30 \%$ of the cases [5]. Because of the complex nature of recurrent patellar instability and associated dysplastic features, comprehensive preoperative evaluation is crucial for determining appropriate treatment modality to prevent such adverse events as recurrence, pain and knee contracture.

The objective of the study was to develop a preoperative diagnostic protocol for optimal surgical treatment of pediatric patients with severe recurrent patellar dislocation to enable complication rate reduction at a short- and long-term follow-up.

[D Kotelnikov G.P., Ryzhov P.V., Lartsev Yu.V., Zuev-Ratnikov S.D., Kudashev D.S., ZelterP.M., Shmelkov A.V., Bagdulina O.D. Preoperative planning of severe recurrent patellar dislocation in children. Genij Ortopedii, 2020, vol. 26, no 3, pp. 319-324. DOI 10.18019/1028-4427-2020-26-3-319-324 


\section{MATERIAL AND METHODS}

Between 2015 and 201754 patients diagnosed with patellar dislocation were treated at the pediatric orthopaedic and trauma department of Samara State Medical University hospital. Nine patients had firsttime patellar dislocation and received nonoperative treatment. All the rest participants were diagnosed with recurrent patellar instability and 37 had severe involvement as classified by Volkov grading system. The patients' age ranged from 10 to 16 years with the mean age of 12.6 years. Preoperative assessment included standard radiographs of the knee and axial view of the patella, computed tomography of the knees and photoplantography of the feet. The factors contributing to patellar lateralization including subluxation and dislocation were shown to comprise structural and functional changes in the patellofemoral articulation, anomalies/dysplasia leading to dysplastic syndromes with resultant patellar instability, subluxation, dislocation. Parameters characterizing structural features of the femoral trochlea, patella, tibia include:

1) Q-angle muscle allows assessment of the limb structure, limb alignment, muscle balance with patellar tracking, its location and tilt (normal Q-angle is 20 degrees) [1];

2) The Insall-Salvati ratio (1971): ratio of the length between the lower pole of the patella and the tibial tuberosity to the length between the greatest pole-to-pole length (normal: 1.02-1.2) [6];

3) The Blumensaat's line (1938) also known as the intercondylar line normally intersects the lower pole of the patella [6];

4) Blackburne-Peel ratio (1977) is used to assess patellar height: the ratio of the perpendicular height of the distal part of the joint surface of the patella, up to a line projected anteriorly to the surface of the tibial plateau and the length of the joint surface of the patella on the lateral view. Normal value $=$ ratio of 0.8; patella baja: < 0.6; patella alta: > 1.0 [6];

5) Vertical position of the patella: ratio of the greatest diagonal length of the patella to the distance from the anterior point on the physis of the proximal tibial metaepiphysis to the lower pole of the patella on the lateral radiograph. Normal value $=$ ratio of 1.2 ; patella alta: $<1.1$; patella baja: $>1.3$ [6];

6) The Wiberg and Baumgartl opening angle of the patella. Normal value of 120-140 degrees. The Wiberg and Baumgartl angle measuring less than 120 degrees indicates to pathological morphology [6];

7) The congruence angle on Merchant view (1974) formed between the line bisecting the trochlear groove angle and the line going from the vertex of the trochlear angle to the eminence or crest between the patellar facets. Deviation of 8 degrees to the medial side is interpreted as a pathology and denoted as «+» [6];

8) Lateral patellofemoral angle on Laurin view (1979) formed between a tangential line through femoral condyles and the plane of the lateral trochlear facet. A patellofemoral angle opening laterally is considered normal. In subluxation patellofemoral angle is $0^{\circ}$ and opens medially [6];

9) The opening angle of the sulcus on Ficat view normally measures 143 degrees or it can be defined as trochlea groove angle on Merchant view (1974) that normally measures not more than 140 degrees. The trochlear groove angle $>140^{\circ}$ indicates to a pathology [6];

10) TT-TG is ratio of tibial tubercle - trochlea groove distance [7];

11) Femoral anteversion angle is the angle formed by a line anteriorly projecting from the femoral neck. Anteversion averages between 10 and 12 degrees [7].

In the study, femoral anteversion angle was measured using the technique developed by Federal State Institution 'Nizhegorodsky Research Institute for Trauma and Orthopaedics' Federal Agency for High Technology Medical Assistance, patent № 2350268 of 27.03.2009.

The above parameters with exception of that numbered 11 were based on local diagnosis, i.e. dysplastic features were evaluated within the knee, in the patellofemoral joint. Our findings indicated to dysplastic manifestations revealed in the knee and in the foot of pateints with severe recurrent patellar dislocation. Physical examination of 37 patients showed myelodysplastic flat and valgus deformity of the foot. Flat and valgus deformity of the foot was also seen on lateral weightbearing foot radiographs and photoplantographs. Photoplantographs demonstrated calcaneal valgus ranging between 12 and 15 degrees $(n=19)$ and measuring more than 15 degrees $(n=8)$ and indicated to high grade dysplasia. Flat and valgus deformity of the foot is to be considered when planning postoperative rehabilitation program.

Underestimated severity of dysplastic changes in the joint and selection of inadequate treatment strategy may result in disturbed biomechanics of the knee joint and progression of destructive pathological processes in the joint with associated pain, chronic synovitis and impaired function of the limb [5]. 


\section{RESULTS}

Pathological changes in all the 11 parameters were detected in 37 patients (Table 1). Radiographic and photoplantographic evaluation showed moderate and severe flat and valgus deformity of the foot.

Therefore, a combination of the measurements can be indicative of the severity of the disease and a complicated multicomponent deformity of the patellofemoral joint. Multicomponent boneplasty operative procedure was indicated for the cohort of patients with multiplanar changes in the patellofemoral joint detected with comprehensive diagnostic workup [7]. The condition could be addressed with bifocal osteotomy: correcting proximal intertrochanteric oosteotomy of the femur and correcting distal supracondylar osteotomy of the femur $[1,7]$. Femoral neck anteversion angle was the measurement governing the choice of the osteotomy level. Proximal femoral osteotomy was produced with the femoral anteversion angle of more than 25 degrees [7]. The combination of the measurements is indicative of the severity of the disease but operative correction of anatomical relationship in the knee joint relied more on the changes in the measurements of Q-angle, Insall-Salvati ratio, congruence angle on Merchant view, TT-TG distance, femoral neck anteversion. Extent of the correction was calculated individually for the patients determining degrees of varus with Q-angle, tibial tubercle medialization with TT-TG ratio, distalization length with Insall-Salvati ratio. Rotational alignment of the femoral condyles was a major concern with the surgical intervention. We could not find a technique for calculation of femoral condyle rotation in the available Russian and foreign literature and for the reason, a technique for individual calculation of femoral condyle realignment was developed at the Krasnov department of traumatology, orthopaedics and extreme surgery, FSBEI HE Samara State Medical University of the RF Ministry of Health for surgical treatment of severe recurrent patellar dislocation. Certificate of acceptance № 20191104298 dtd 15.02.2019 was obtained for the technique.

Calculations were produced as a part of preoperative workup. The patients underwent supracondylar derotational varus osteotomy of the femur combined with tibial tubercle medialization. From anatomical and functional point of view multiplanar surgical maneuvres were performed to address major components of the deformity in severe recurrent patellar dislocation. The study received a favourable opinion from the relevant research bioethics committee of the Samara State Medical University on 08.11.2017. The study was performed in accordance with ethical principles for medical research involving human subjects stated in the Declaration of Helsinki. Written informed consent was obtained from legal representatives of pediatric patients prior to surgical treatment.

Table 1

Pathological changes detected in patients $(n=37)$

\begin{tabular}{|c|c|c|c|}
\hline Measurement & Normal value (0) & Average value in patients (I) & $\mathrm{p}(0-\mathrm{I})$ \\
\hline Q-angle & Up to 20 degrees & $28 \pm 0.40$ degrees & $<0.001$ \\
\hline Blumensaat's line & Projected to the lower pole of the patella & $\begin{array}{l}\text { Never seen projected in the } \\
\text { patients }\end{array}$ & \\
\hline Insall-Salvati ratio & $1.02-1.2$ & $1.5 \pm 0.14$ & $<0.001$ \\
\hline $\begin{array}{l}\text { Blackburne-Peel ratio (patellar } \\
\text { height) }\end{array}$ & 0.8 & $1.2 \pm 0.07$ & $<0.001$ \\
\hline Vertical position of the patella & $1.2-1.3$ & $0.9 \pm 0.02$ & $<0.001$ \\
\hline $\begin{array}{l}\text { Wiberg-Baumgartl opening } \\
\text { angle of the patella }\end{array}$ & $120-140$ & $150 \pm 0.75$ & $<0.001$ \\
\hline $\begin{array}{l}\text { Congruence angle on } \\
\text { Merchant view }\end{array}$ & $\begin{array}{l}\text { medial deviation by } 8 \text { degrees is } \\
\text { considered normal and the angle is } \\
\text { negative, lateral deviation of more than } 8 \\
\text { degrees is considered a pathology and the } \\
\text { angle is positive }\end{array}$ & $11 \pm 0.23$ degrees & \\
\hline $\begin{array}{l}\text { Opening angle of the sulcus } \\
\text { on Ficat view }\end{array}$ & 138 degrees & $144 \pm 0.65$ degrees & $<0.001$ \\
\hline $\begin{array}{l}\text { Lateral patellofemoral angle } \\
\text { on Laurin view }\end{array}$ & The angle always opens medially & The angle opens medially & \\
\hline TT-TG ratio & $12 \mathrm{~mm}$ & $22 \pm 0.17 \mathrm{~mm}$ & $<0.001$ \\
\hline $\begin{array}{l}\text { Femoral neck anteversion } \\
\text { angle }\end{array}$ & 10-12 degrees & $13.8 \pm 0.4$ degrees & $<0.001$ \\
\hline
\end{tabular}


A clinical instance of a 16-year-old patient is presented for illustration. Preoperative evaluation of the patient revealed pathological disorders in the right knee joint and changes in all the above parameters as typical for recurrent patellar dislocation. Diagnostic workup indicated to the changes being characteristic of a severe deformity with the Volkov classification. Radiographs and computed tomography revealed severe multiplanar dysplastic changes in the right knee joint as shown in Figures 1, 2 and 3. The patient had also flat and valgus deformity of the feet with the calcaneal valgus of $10^{\circ}$ on the left and $15^{\circ}$ on the right. Considering the complexity of multiplanar dysplastic changes in the right knee joint the patient was surgically treated with supracondylar derotational varus osteotomy of the femur combined with tibial tubercle medialization. The results are presented in Figures 4, 5 and 6.

Calcaneal valgus on the right side (at the side of surgical intervention) measured $8^{\circ}$ postopereratively.

Preoperative and postoperative diagnostic parameters are presented in Table 2.

No complications were seen in 32 patients at a long term and re-dislocation occurred in one case. Four patients developed a $110^{\circ}$ contracture of the knee joint with passive and active extension in the knee measuring up to 10 degrees, and intermittent pain. However, the patients had nearly normal relationships in the patellofemoral joint and complications resulted from inadequate postoperative rehabilitation.

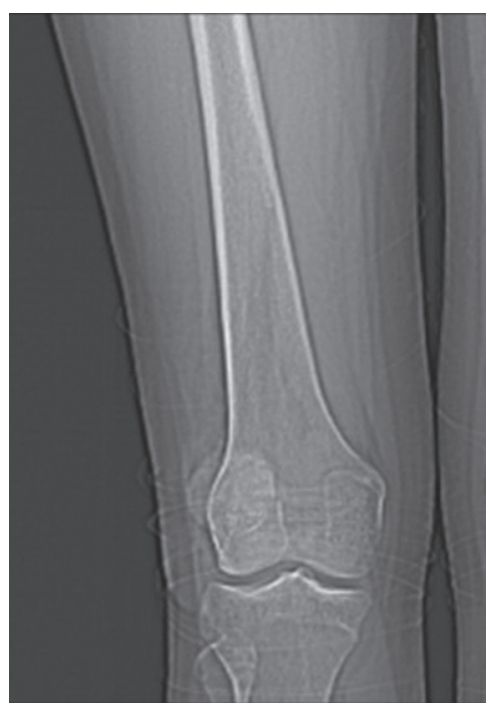

Fig. 1 Preoperative AP view of the right knee joint showing valgus alignment of the femoral condyles with regard to the femoral axis and patellar lateralization

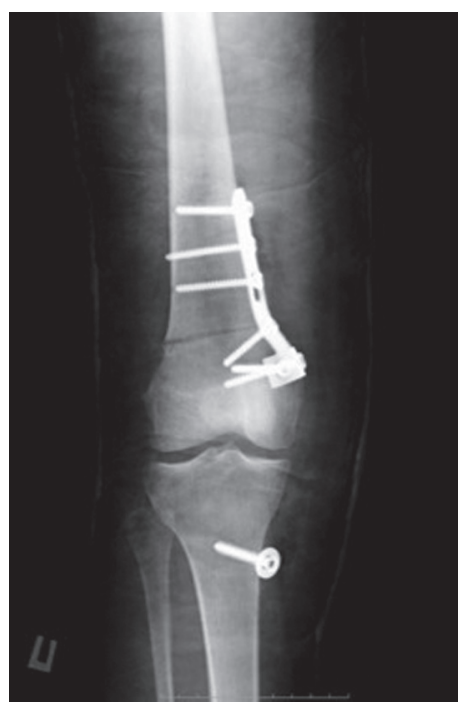

Fig. 4 Postoperative AP view of the right knee joint showing valgus of the femoral condyles realigned and patellar lateralization eliminated

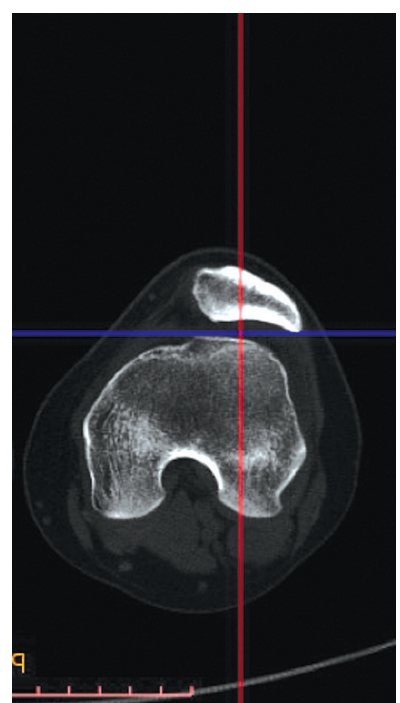

Fig. 2 Preoperative computerized axial tomography scan of the right knee joint, bone window showing patellar lateralization, dysplastic changes in the lateral condyle and intercondylar trochlea groove of femur

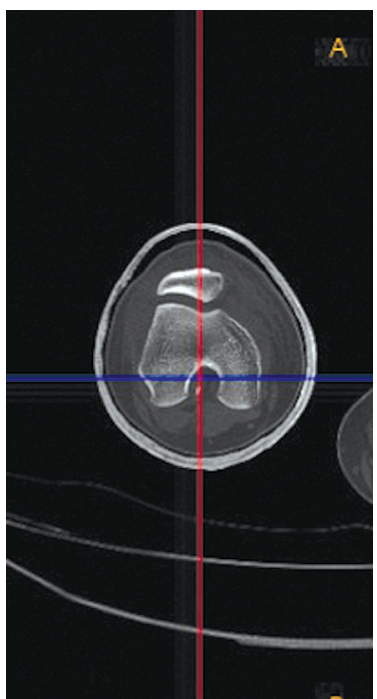

Fig. 5 Postoperative computerized axial tomography scan of the right knee joint, bone window showing anatomical relationship in the patellofemoral joint restored

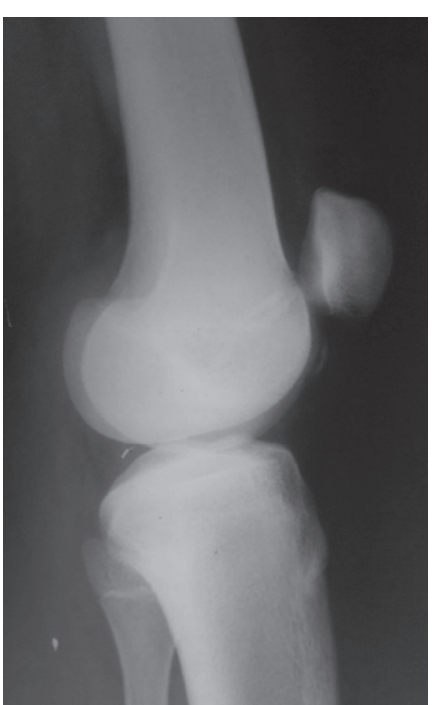

Fig. 3 Preoperative lateral view of the right knee joint showing signs of patella alta

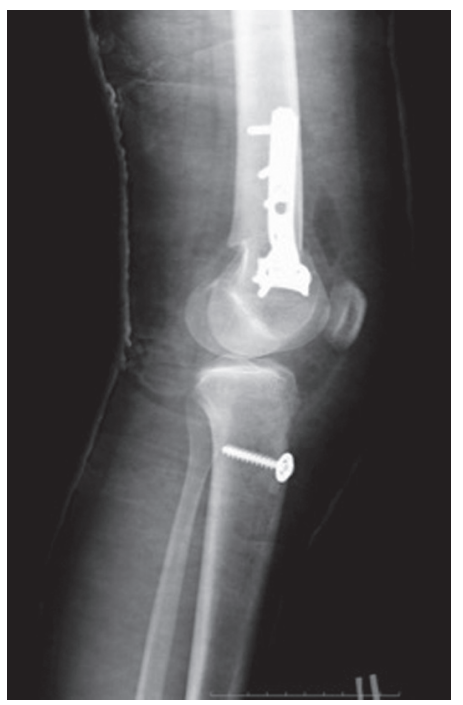

Fig. 6 Postoperative lateral view of the right knee joint showing no signs of patella alta 
Preoperative and postoperative diagnostic parameters of the patient

\begin{tabular}{|l|c|c|}
\hline \multicolumn{1}{|c|}{ Diagnostic parameter } & Pre-op & Post-op \\
\hline Q-angle & 26 degrees & 18 degrees \\
\hline Insall-Salvati ratio & 1.5 & 1.2 \\
\hline Congruence angle on Merchant view & 11 degrees $«+»$ & 4 degrees \\
\hline TT-TG distance & $25 \mathrm{~mm}$ & \\
\hline Femoral head anteversion & 14 degrees & 14 degrees \\
\hline Patellar lateralization angle calculated using the new technique & 55 degrees & 40 degrees (normal) \\
\hline
\end{tabular}

\section{DISCUSSION}

Patellofemoral dysplasic changes in the human musculoskeletal system are considered to be a major predisposing factor for patellar dislocation [8]. Preoperative evaluation of the patients using the algorithm described in the article indicated to severe dysplastic changes in the knee joint as a major cause of recurrent patellar dislocation. There are about 150 operative techniques known to be used for patellar dislocation. However, recurrence and complication rate is reported to be as high as $36.1 \%$ according to the Russian and foreign literature [8]. The diagnostic algorithm we used for severe recurrent patellar dislocation in pediatric patients revealed multiplanar dysplastic changes in the knee joint with operative treatment aimed at the correction of a single, most severe deformity. Such an approach fails to provide a complete recovery of all the relationships in the patellofemoral joint and results in high recurrence and complication rate. Combined surgical interventions are practical for multicomponent dysplastic changes in the pediatric knee joint in severe recurrent patellar dislocation. Supracondylar derotational varus osteotomy of the femur combined with tibial tubercle medialization was shown to restore anatomical relationships in the patellofemoral joint in axial, sagittal and coronal planes. Long-term follow-ups demonstrated $86.5 \%$ positive results and $13.5 \%$ poor outcomes that are superior to the reported recurrence and complication rate of $36.1 \%$ according to the Russian and foreign literature [8].

\section{CONCLUSION}

The thorough diagnostic workup is crucial for identifying treatment strategy of a recurrent patellar dislocation due to a complex structure of the patellofemoral joint and a multicomponent dysplastic changes in the knee and adjacent parts of the lower limb. Surgical treatment is to to be complied with the complexity of multicomponent deformity of the patellofemoral joint and dysplastic changes in other joints including flat and valgus foot deformity to avoid postoperative complications. Combining bone and tendon and muscle plasty procedures surgical strategy and extent of correction were identified with the algorithm as follows:

1) severity of the condition to be determined with the 11 parameters described above;

2) the level of femoral osteotomy to be identified for a severe condition;

3 ) if osteotomy is needed in the distal femur the extent of correction to be calculated individually using Q-angle, TT-TG radio, Insall-Salvati ratio, and rotational alignment of the femoral condyles can be calculated with the new technique.

The authors declare that there is no conflict of interest.

\section{REFERENCES}

1. Solomon L., Warwick D., Nayagam S. (eds.). Apley's System of Orthopaedics and Fractures. Ninth Ed. London, Hodder Arnold An Hachette UK Company. CRC Press, 2010. 992 p.

2. Dezhur D.G., Anosov V.S., Britko A.A. Plastika bloka bedrennoi kosti v lechenii patsientov s privychnym vyvikhom nadkolennika [Femoral block plasty in treatment of patients with habitual patella dislocation]. Meditsinskie Novosti, 2013, no. 8, pp. 56-59. (in Russian)

3. Gafarov Kh.Z. Sposob lecheniia vrozhdennogo vyvikha nadkolennika [A method of treating the patella congenital dislocation]. Prakticheskaia Meditsina, 2016, no. 4-1, pp. 74-78. (in Russian)

4. Shevtsov V.I., Buravtsov P.P. Redkaia forma vrozhdennogo vyvikha nadkolennika [Patellar congenital dislocation of rare form]. Genij Ortopedii, 2009, no. 1, pp. 110-113. (in Russian)

5. Iakovlev A.B., Alekseeva N.V., Bolshakov G.A. Tenodez po Galleazzi s artroskopicheskim ispolzovaniem reliza pri operativnom lechenii privychnogo vyvikha nadkolennika [Tenodesis according to Galleazzi with release arthroscopic use in surgical treatment of habitual dislocation of the patella]. Biulleten Vostochno-Sibirskogo Nauchnogo Tsentra Sibirskogo Otdeleniia Rossiiskoi Akademii Meditsinskikh Nauk, 2011, no. 4-1 (80), pp. 222-224. (in Russian) 
Genij Ortopedii, Vol. 26, no 3, 2020

6. Klimenko I.G. Displasticheskii retsidiviruiushchii vyvikh nadkolennika (sindrom narusheniia ravnovesiia) [Dysplastic recurrent dislocation of the patella (equilibrium disorder syndrome)]. Biulleten Vostochno-Sibirskogo Nauchnogo Tsentra Sibirskogo Otdeleniia Rossiiskoi Akademii Meditsinskikh Nauk, 2013, no. 5 (93), pp. 29-32. (in Russian)

7. Johnson D., Amendola N.A., Barber F., Field L., Richmond J., Sgaglione N. Operative Arthroscopy. $4^{\text {th }}$ Ed. New York, Lippincott Williams \& Wilkins, 2012, 1248 p.

8. Buravtsov P.P., Gorevanov E.A., Muradisinov S.O. Metody lecheniia vyvikha nadkolennika v otechestvennykh i zarubezhnykh publikatsiiakh (obzor literatury) [The techniques for treatment of patellar dislocation in foreign publications and in those of our country (Review of the literature)]. Genij Ortopedii, 2006, no. 3, pp. 69-72. (in Russian)

Рукопись поступила 20.11.2019

\section{Information about authors}

1. Gennadii P. Kotelnikov, M.D., Ph.D., Professor, Academician of RAS, Samara State Medical University, Samara, Russian Federation

2. Pavel V. Ryzhov, M.D., Ph.D., Samara State Medical University, Samara, Russian Federation, Email: ortos1@yandex.ru

3. Yuriy V. Lartsev, M.D., Ph.D., Professor, Samara State Medical University, Samara, Russian Federation, Email: lartcev@mail.ru

4. Sergey D. Zuev-Ratnikov, M.D., Ph.D., Samara State Medical University, Samara, Russian Federation, Email: stenocardia@mail.ru

5.Dmitriy S. Kudashev, M.D., Ph.D., Samara State Medical University, Samara, Russian Federation, Email: dmitrykudashew@mail.ru

6. Pavel M. Zelter, M.D., Ph.D., Samara State Medical University, Samara, Russian Federation

7. Andrey V. Shmelkov,

Samara State Medical University, Samara, Russian Federation, Email: phenicks-fire@mail.ru

8. Olga D. Bagdulina,

Samara State Medical University, Samara, Russian Federation, Email: Olga.bag.724@mail.ru 